\title{
Intraoperative Findings during Canal Wall Down Mastoidectomy in Children
}

\author{
Shrestha $\mathbf{S}^{1}$, Kafle $\mathbf{P}^{2}$ \\ ${ }^{1}$ Dr. Sangita Shrestha, MBBS, MS, Assistant Professor, ${ }^{2}$ Dr. Prakash Kafle, MBBS, MS, Assistant Professor, Department \\ of ENT and Head and Neck Surgery, Kathmandu Medical College Teaching Hospital, Sinamangal, Kathmandu.
}

Address for correspondence: Dr. Sangita Shrestha, E-mail: sangitadr@yahoo.co

\begin{abstract}
Objective: The main objective of this study is to assess the intraoperative finding during canal wall down mastoidectomy in paediatric patients undergoing surgery for unsafe type of chronic suppurative otitis media (CSOM) attending ENT OPD of Kathmandu Medical College. Materials and Methods: Fifty patients of age group 4 to 13 years who were suffering from unsafe type of CSOM with or without cholesteatoma were taken for the study. The study period was two years from April 2007 to March 2009. The operative findings like extent of cholesteatoma in different location of middle ear cleft, mastoid bony landmarks, and ossicular chain condition and otogenic complication were identified during canal wall down mastoidectomy. Result: Of the 50 patients $32(64 \%)$ were boys and $18(36 \%)$ were girls. The age ranged from 4 years to 13 years. Majority of patients had cholesteatoma with granulation diseases $(72 \%)$ followed by granulation diseases (16\%). Involvement of disease in attic, aditus, antrum and mesotympanum were found to be high in majority of cases ( $82 \%$ ) with high percentage of necrosis of incus $(56 \%)$. Conclusion: The primary disease found in patients undergoing canal wall down mastoidectomy (CWDM) was cholesteatoma combined with granulation in $72 \%$, granulation in $16 \%$ and cholesteatoma in $12 \%$.
\end{abstract}

Key words: Canal Wall Down, ENT, Mastoidectomy, Chronic Suppurative Otitis Media (CSOM)

\section{Introduction}

C hronic suppurative otitis media is one of the most common diseases in our set up. There are two types of chronic suppurative otitis media: Tubotympanic and atticoantral or unsafe type. Of the various surgical techniques for management of unsafe type of Chronic Suppurative Otitis Media (CSOM), Canal wall down mastoidectomy (Canal Wall Down) is one of them. It involves taking down the posterior canal wall to the vertical facial nerve, exteriorizing the mastoid cavity into external auditory canal. It includes modified radical mastoidectomy, radical mastoidectomy and atticotomy. The modified radical mastoidectomy in which the middle ear space is preserved and tympanic membrane remnant thereof and ossicular remnant (usually malleus handle and stapes) are retained. The radical mastoidectomy is an operation performed to eradicate all the middle ear and mastoid disease in which mastoid antrum air cell system, aditus ad antrum, attic and middle ear are converted into a common cavity, exteriorized to the external auditory canal. The Eustachian tube plugged. Meatoplsty is also the component of CWD mastoidectomy ${ }^{1-3}$.

This study was done to find out the extent of primary diseases (cholesteatoma and granulation disease) in different locations of the middle ear cleft during surgery. The study was conducted on paediatric patients who had undergone CWD mastoidectomy, in the Department of Ear Nose and Throat (ENT), Kathmandu Medical College, Teaching Hospital.

\section{Materials and methods}

This is a retrospective study involving 50 patients who were of the age group from 4 years to 13 years, and had undergone canal wall down mastoidectomy for unsafe type of CSOM. The study period was two years from April 2007 to March 2009. Patients fit for general anesthesia were admitted one day before the surgery. They were started on oral antibiotic (Amoxycillin 
or amoxyclave) one day prior to surgery, and were continued for ten days post operatively. The ear was prepared and draped using sterile technique. Patients were operated on with either post aural approach or with endaural approach. All patients underwent canal wall down procedure under general anesthesia. Either radical or modified radical mastoidectomy was done depending upon the preoperative hearing status of the patients. Temporalis muscle fascia was used as grafting material.

During operation typeof primary disease, extent of disease in the middle ear cleft and ossicular status was observed. Otogenic complication and landmark of mastoid boundaries were also identified.

\section{Results}

Of the 50 patients, $32(64 \%)$ were boys and 18 $(36 \%)$ were girls. The majority of the patients were boys. The age ranged from 4 years to 13 years. Foul smelling ear discharge with or without polyp and hearing loss were main clinical finding in majority of cases. Otogenic complication like lateral sinus thrombophlebities, post aural abscess and mastoid fistula were seen in very few cases.

Out of 50 patients, the primary disease found was cholesteatoma with granulation in 36 patients $(72 \%), 8$ patients $(16 \%)$ had granulation and 6 patients $(12 \%)$ had cholesteatoma (Table 1). The intraoperative finding of extent of disease in different location of middle ear cleft like attic, antrum, and mesotympanum and hypotympanum are shown as in (Table 2). Involvement of all the location like tympanic and mastoid cavities were seen in majority of cases

Out of 50 patients $18(36 \%)$ children had dural plate dehiscent and $12(24 \%)$ had low lying dura. Six (12\%) children had sinus plate dehiscent. Facial nerve was dehiscent was found only in 2 patients.

Malleus was noted to be intact in majority of cases. The incus, however, was noted to be eroded in 28 patients (56\%). Absence of stapes suprastructure was seen in 12 patients (24\%) (Table 4 ).

Table 1: Showing type of disease found in the middle ear cleft during surgery.

\begin{tabular}{|l|c|}
\hline Type of Disease & Number of patients $(\mathbf{n = 5 0})$ \\
\hline $\begin{array}{l}\text { Cholesteatoma with } \\
\text { granulation }\end{array}$ & 36 \\
\hline Granulation & 8 \\
\hline Cholesteatome & 6 \\
\hline
\end{tabular}

Table 2: Showing Extent of disease identify during CWD surgery $(n=50)$.

\begin{tabular}{|l|c|c|}
\hline \multirow{2}{*}{\multicolumn{1}{|c|}{ Extent of Disease }} & \multicolumn{2}{|c|}{$\begin{array}{c}\text { Children (4-13 years, } \\
\mathbf{n}=\mathbf{5 0}\end{array}$} \\
\cline { 2 - 3 } & Number & $\begin{array}{c}\text { Percentage } \\
\text { (\%) }\end{array}$ \\
\hline Attic/Aditus/Antrum & 9 & 18 \\
\hline $\begin{array}{l}\text { Attic/Aditus/Antrum/ } \\
\text { Mesotympanum (tympanic } \\
\text { and mastoid cavities) }\end{array}$ & 41 & 82 \\
\hline Mesotympanum & 0 & 0 \\
\hline
\end{tabular}

Table 3: Showing the operative findings of mastoid bony landmarks $(n=50)$.

\begin{tabular}{|l|c|c|}
\hline \multirow{2}{*}{$\begin{array}{l}\text { Landmark of Mastoid } \\
\text { Boundary }\end{array}$} & \multicolumn{2}{|c|}{ No of pt (50) } \\
\cline { 2 - 3 } & No. & (\%) \\
\hline Facial Nerve canal & 48 & $(96 \%)$ \\
\hline Intact & 2 & $(4 \%)$ \\
\hline Dehiscent & 50 & $(100)$ \\
\hline Lateral Semicircular Canal & \multicolumn{2}{|l}{} \\
\hline Intact & 0 & $(0)$ \\
\hline Dehiscent & \multicolumn{1}{|l}{} \\
\hline Sinus Plate & 44 & $(88)$ \\
\hline Intact & 6 & $(12 \%)$ \\
\hline Dehiscent & 6 & $(60)$ \\
\hline Dural Plate & 18 & $(40)$ \\
\hline Intact & \multicolumn{2}{|l}{} \\
\hline Dehiscent
\end{tabular}

Table 4: Showing operative findings of Ossicular Chain Condition $(n=74)$.

\begin{tabular}{|c|c|c|}
\hline \multirow{2}{*}{$\begin{array}{l}\text { Operative } \\
\text { Findings }\end{array}$} & \multicolumn{2}{|c|}{ No. of patients $=50$} \\
\hline & Number & Percentage (\%) \\
\hline \multicolumn{3}{|l|}{ Malleus } \\
\hline Intact & 38 & 76 \\
\hline Eroded & 3 & 6 \\
\hline Absent & 9 & 18 \\
\hline \multicolumn{3}{|l|}{ Incus } \\
\hline Intact & 0 & 0 \\
\hline Eroded & 28 & 56 \\
\hline Absent & 22 & 44 \\
\hline \multicolumn{3}{|l|}{ Stapes } \\
\hline Intact & 38 & 76 \\
\hline Eroded & 0 & 0 \\
\hline Absent & 12 & 24 \\
\hline
\end{tabular}

\section{Discussion}

In this study an attempt has been made to find out the extent of diseases in different location of middle ear cleft undergoing surgery for unsafe type of CSOM. The choice of surgical technique for unsafe CSOM depends on numbers of factors. In our series all children underwent canal wall down mastoidectomy because of the extensive nature of disease and also because most of them had come from remote places thus would not be able to come for regular follow up. 
We followed the standard categories of age included for paedriatics population similar to Josef $P G$ et $\mathrm{al}^{1}$. They included children 0 to 12 years old $(n=17$, $21 \%$ ). In our series age categories were similar and the numbers of children were 50 .

A10 years study done by Schuring et $\mathrm{al}^{2}$ used three categories of age: children, 0 to 9 (our paediatric patients were upto13 years), adolescents 10 to 15 years and adults 16 years above. Primary diseases found during CWD mastoidectomy were cholesteatoma combined with granulation in $72 \%$ of patients and granulation in $16 \%$ followed by cholesteatoma in $12 \%$. Bunne and Raivio $^{3}$ described 147 mastoidectomies in 16years old and younger with discharging ear during 1981 to 1986. Out of which, only $26(18 \%)$ patients had have cholesteatoma. Josef $\mathrm{PG}$ et $\mathrm{al}^{1}$, did a similar study and observed $15(47 \%)$ children and adolescents each with cholesteatoma in the middle ear cleft during CWD mastoidectomy, whereas 16 adult patients (33\%) had cholesteatoma. They concluded that cholesteatoma and cholesteatoma with granulation were common primary pathology found in middle ear cleft. But in our series cholesteatoma with granulation $(72 \%)$ was common intraoperative finding during CWD mastoidectomy. Therefore high incidence of cholesteatoma with granulation was found in middle ear cleft in paediatric patients.

Extent of disease is also identified during surgery. The involvement of attic, antrum and meso tympanum was seen in 41 patients (82\%). Similarly observation by Josef PG et al ${ }^{1}$ was found in their extensive study. However our series showed more extensive disease compared to them. Mobeen A et $\mathrm{al}^{4}$ found that the location of cholesteatoma was in the epitympanum in11 patients $(10 \%)$, mesotympanum in 7 patients $(7 \%)$, attic and meso/hypotympanum in 32 patients(33\%) and attic and antrum 35 patients (33\%), and all tympanic and mastoid cavities in 21 patients (20\%). In our series the location of primary disease was involved in all tympanic and mastoid cavities in $82 \%$. The intraoperative finding in the mastoid bony landmark, showed a high incidence of dehiscence of one and more bony landmarks; dural dehiscent was seen in 18 patients whereas dehiscent of sinus plate was found in 6 patients. Different studies have reported that children had high incidence of dural dehiscent compared to adult and adolescents.

By ossicular chain status, malleus was found to be intact in majority of the patients (Table 4). Josef PG et al ${ }^{1}$ also showed the same findings. In another study done by Kurien et $a l^{5}$ they found that malleus was least affected in both the age groups, whereas there was significant involvement of stapes (95\%) in children compared with adults. In our series it was found that most of the patients had erosion of incus (56\%). In our series suprastructure of the stapes was present in $38(76 \%)$ cases. Those who had foot plate only were planned for ossiculoplasty for hearing at later date.

Otogenic intracranial complications are well documented elsewhere and have high prevalence in low socio economic class ${ }^{6,7,8}$. Intracranial complication arising from otitis media caused 25 of 1000 deaths in preantibiotic era ${ }^{8,9}$. These complications are extremely rare now a day due to the advent of new and effective anti microbial agents. Lateral sinus thrombophlebitis was next most common otogenic complication resulting in high mortality whereas meningitis was the most common intracranial complication as observed by Samuel et. al. ${ }^{7,8}$ In our series otogenic complications were comparatively infrequent. Lateral sinus thrombophlebitis was found in 3 cases. Overall study showed that Cholesteatoma along with granulation tissue was found in the majority of cases followed by granulation in our study.

\section{Conclusion}

The primary disease found during canal wall down mastoidectomy in children was cholesteatoma combined with granulation in $72 \%$ of cases, granulation in $16 \%$ cases and cholesteatoma in $12 \%$ of cases. It was also concluded that tympanic and mastoid cavities (82\%) were involved with disease mainly with choleasteatoma along with granulation tissue, whereas granulation was more commnly seen in mesotympanum. Incus was the commonest ossicle eroded by the disease process followed by stapes suprastructure.

\section{Acknowledgement: None \\ Funding: None \\ Conflicting Interests: None \\ Permission from IRB: Yes}

\section{References}

1. Josef PG, Dubey SP. Canal down masoidectomy: Experience in 81 cases. Otolo Neurotol 2001;22:451-56.

2. Schuring AG, Lippy WH, Rizer FM, et al. Staging for cholesteatoma in the child, adolescent and adult. Ann Otol Rhinol Laryngol 1990;99:256-60.

3. Bunne $M$, Raivio $M$. Pitfalls in diagnosis and treatment of cholesteatoma in children. In: Tos M, Thomsen J, Peitersen E, eds. Cholesteatoma and Mastoid Surgery. Copenhagen Cholesteatoma Conference Amsterdam: Kugler and Ghedini, 1989; 651- 6. 
4. Mobeen A. Shirazi, MD, et al. Surgical treatment of pediatric cholesteatoma: The Laryngoscpoe 116: sept 2006.

5. Kurien M, Job A, Mathew, et al. Otogenic intracranial abscess: concurrent craniotomy and mastoidectomy: changing trends in a developing country. Arch Otolaryngol Head Neck Surg 1998;124:1356-66.

6. Singh B, Maharaj TJ. Radical mastoidectomy: its place in otitis intracranial complications. J Laryngol Otol 1993;107:1113-18.
7. Samuel J, Fernandes CMC, Stenberg JL. Intracranial otogenic complications: a persisting problem. Laryngoscope 1986;96:272-8.

8. Myrphy T, Boydston W. Lateral sinus thrombosis. Otolarygol Head Neck Surg 1997;117:134-7.

9. Ricardo A, Godinho et al. Pediatric cholesteatoma: Canal Wall Window Alternative to Canal Wall Down Mastoidectomy: Otol Neurotol 26:466-471,2005.

10. M. Sadoghi, P.D. et al. Intraoperative finding in revision mastoid surgery: Acta. Medica Iranica 2007,45(5);373-376.2007.

\section{How to cite this article?}

Shrestha S, Kafle P. Intraoperative findings during Canal Wall down Mastoidectomy in Children. J Nepal Paediatr Soc 2011;31(3):184-187. 